\title{
Editorial
}

\section{The challenges of a small medical journal to have an international recognition in Indonesia: editors' perspectives}

Hans Joachim Freisleben, ${ }^{1,2}$ Felix Firyanto Widjaja, ${ }^{1}$ Farrokh Habibzadeh ${ }^{1,3}$

Check for updates

Most of the journals in Indonesia are small journals published by their own institutions or societies. It is tough for us to obtain an international recognition. As stated by Ana and Matko Marusic from Croatian Medical Journal, small journals "cover a wide array of journals that are outside the mainstream and published in the hope that they will be read and recognized internationally although in reality they achieve mostly a local readership". ${ }^{1}$ There are some proofs that a journal has an international recognition, such as publishing several authors from abroad, getting indexed in Medline, Scopus, or Web of Science, and having more citations from outside articles than from the journal itself. Hence, the editors of the journal need to solve these issues to achieve this international recognition.

First, we need to improve the quality of scientific journals. This quality is determined by having virtuous scientific editors who have good competencies. ${ }^{2}$ Moreover, having submissions of manuscripts with good scientific quality is beyond the capability of the editors, themselves. It starts with the research system in higher education, mostly at universities. During the last three decades, we had an everlasting discussion in Indonesia about "ongoing research projects" by the departments and professors or "individual research" by the master and doctoral students. In most countries with high profile research, university departments, institutes or professors provide and offer long-term research projects to students to join in. In these research groups, profound basic knowledge exchange exists with a broad spectrum of students and post-docs often from different scientific backgrounds. In Indonesia, students in the master or doctoral study programs often create their own research idea and ask some professors to supervise their projects. This research may work out for a thesis, but is possibly not enough for a good quality publication; it often lacks methodological and literature background because the supervisors, themselves, are not always experts in this field.
Choosing the right research question/hypothesis is therefore of paramount importance in gaining acceptance by prestigious international journals. The same is true for a journal. The good scientific quality of the articles published by a journal determines the likelihood of the journal being accepted by reputable indexing systems or make it more recognizable. Working on (and publishing) studies using high-tech molecular methods and competing with researchers working in well-equipped research centers (mostly in the West) is fighting an uphill battle and would bring us almost nothing but discouragement.

An other important issue is that the system in Indonesia expects publications and practical results that are useful for the public within a very short period. Basic research often does not yield practical results within short time and may therefore no longer be funded after the first year. Moreover, the funding authorities only provide a short period to propose, conduct, and report a research; we know that even for reporting in a journal, it may take years for researchers to publish a result.

Why should a prestigious indexing system (mostly based in the Western countries) index a journal publishing research which had already been done (most likely with a better standard) by large research groups? To encourage the indexing systems to select our journal for coverage, we should give them something they do not have (or is at least not easily attainable for them).3,4 For example, the number of patients with tuberculosis in the United States, from coast to coast, ${ }^{5}$ is less than the number of cases in a province in Indonesia such as DKI Jakarta. ${ }^{6}$ Dengue or malaria is another tropical disease that is hyperendemic in Indonesia, while it is rarely seen in European countries. To gain international acceptance by reputable indexing systems, we therefore need to focus our research projects on these issues rather than the fields well-covered by the western research

Copyright @ 2021 Authors. This is an open access article distributed under the terms of the Creative Commons Attribution-NonCommercial 4.0 International License (http:// creativecommons.org/licenses/by-nc/4.0/), which permits unrestricted non-commercial use, distribution, and reproduction in any medium, provided the original author and source are properly cited. For commercial use of this work, please see our terms at https://mji.ui.ac.id/journal/index.php/mji/copyright. 
centers. Besides, considering the large population and the biodiversity, the research in Indonesia has also potential. ${ }^{7}$ Some years ago, a movement has begun to change the situation in Indonesia, but progress is still developing too slow.

Traditionally, the requirements for doctoral programs are diverse, depending on the country, although nowadays most country-specific research and publication systems are strongly influenced or even dominated by the Anglo-American system. In the Dutch system, doctoral dissertations used to compile three to five publications in a wider research project. However, the choice of writing a dissertation or compiling publications is left to the students. This country owns some of the world's largest publishers and has an editor of a well-recommended international journal in almost every university department that allows the students to publish their quality research in one of their journals. Each of these publications has their own value and are connected in the dissertation by English or Dutch intermediate texts.

In contrast, the traditional German system had different requirements for doctoral programs. The dissertation has its own value and is not necessarily submitted for publication in a journal because it is distributed to the German libraries and other universities as an official publication.

Moreover, professor candidates (after dissertation and post-doc training) do not just collect impact points; instead, they have to take 5-6 years of experience as lecturer and head of a research working group for their "habilitation" (an extended second dissertation like a Dr. of Science) to prove their field of expertise. Publications are indeed necessary, but they are not the only and absolute determinant.

In Indonesia, publication in journals, in addition to a thesis or dissertation, is needed, as requested by the Directorate of Higher Education, Ministry of Education and Culture Republic of Indonesia. However, Indonesian journals tend to have a poor scientific and methodological quality and authors often practice "salami tactics", which phenomenon is "indirectly" encouraged by the authorities in order to increase the number of publications. Salami publication is a scientific misconduct that turns research into smallest publishable units. ${ }^{8}$ An article by Indonesian author, Dyna Rochmyaningsih, ${ }^{9}$ entitled "How to shine in Indonesian science? Game the system" had elucidated this an unpleasant aspect and went around the globe as an example of misusing the publishing system in Indonesia.

Another issue to achieve high standards of scientific quality is the regulation of restricting references older than 10 years or publishing research that is older than 5 years. This leads to a phenomenon of poorly referenced or even not referenced Methods sections turning Indonesian manuscripts to "shallow", especially in biomedical or basic medical sciences, because the original methodology often dates back to publications from the last century. Even worse, researchers and authors tend not to read the original literature on classical biomedical methods, because it cannot be used as a reference and hence is considered irrelevant.

Scientific writing and English language are also some issues causing the poor quality of Indonesian journals. Scientific writing is an issue that needs to be anchored; how to make a title, abstract, introduction, methods, results, and discussions is a skill that needs to be finely articulated. Most of the manuscripts submitted to the Medical Journal of Indonesia lack the proper scientific writing standards. Moreover, as English is not the mother-tongue of Indonesian authors, writing in English is troublesome. In this context, it was mentioned that scientists in other Asian countries, such as Japan or Singapore, manage to achieve better publishing scores, although having similar problems with English language. Two reasons may be relevant: firstly, universities in these countries have more foreign professors with research positions who can help at least with proofreading. Just having adjunct professors at Indonesian universities does not appear sufficient for the exchange of knowledge, both in science and the usage of academic English. Secondly, if the scientific contents of a manuscript are important enough to be published, journals may offer help with language editing. What if a poorly designed study is unacceptably presented?

Now assume that the problem with research quality is resolved and our journal receives quality submissions. Is that enough? Another remaining problem is the way the current journal editors handle the manuscripts in the journal office. Almost all of the published articles in small medical journals originate from local universities. Apparently, the journal's main objective is to create a forum for the publication of Indonesian fellows to help them in their academic promotion; publishing a quality journal is not a priority.

mji.ui.ac.id 
Although these two objectives can be attainable, achieving both in the short-term is extremely difficult. We believe, it would be better to publish a successful quality journal. Having a quality journal will automatically help the Indonesian researchers to better present and publish their work.

The geographic diversity of authors and their affiliations are among important factors to the indexing systems. For an example, Farrokh Habibzadeh was the Editor-in-Chief of The International Journal of Occupational and Environmental Medicine (The IJOEM), published in Iran. The journal was successful and entered the Medline since its very first issue. ${ }^{10}$ Meanwhile, the Medical Journal of Indonesia needed 13 years since the first issue to be indexed in Scopus. ${ }^{11}$ One of the most important factors in the success of The IJOEM was the diversity in the editorial board members, authors, and their affiliations. ${ }^{12}$ In most of the issues of the journal, they published only one article from an Iranian institution; others were from other countries.

Another influential factor would be the geographical distribution of the editorial board members. They should be selected from prolific active researchers from centers around the globe. Convincing them to join the board is not always easy, but not impossible. These erudite researchers can help the journal with writing solicited narrative reviews and encouraging their colleagues to submit their work to the journal.

In publishing a quality journal, the presence of a good enthusiastic editorial team is pivotal. They should preferably be familiar with research methodology, scientific writing, technical/copyediting, biostatistics, peer-review, and effective communication with people, among other skills. Moreover, in this millennial era, some small medical journal also needs a person with creativity to help the readers engage with the journal through social media. A person with an economical background is sometimes required to run the finance and think about the "oil" to run the journal.

To increase the quality, the journal is better to limit the number of published articles in each issue. This would help the editor to be more selective. Increasing number of pages of each article is suggested to compensate the few number of articles published. The editors should ask the authors to describe the methodology in more detail so that the published article becomes reproducible. If possible, the authors may be encouraged to provide color figures, photomicrographs, and graphs to help them in presenting the details.

The editors should also try to speed up the reviewing process, preferably by primarily screening the submitted manuscripts in-office without being peer-reviewed and trying to reject at least one-third of them on the fly. Then, choose a few manuscripts with appropriate topic and methodology. Before sending the manuscript out for external review, the editors may contact the authors and provide them with ways they could improve their work. The editors may also help the authors with academic writing and standard presentation of the results. This pre-peerreview process significantly increases the chance of the manuscripts' survival during the external peer-review. Believe us, both the authors and reviewers would be delighted for that.

All editors and editorial staff need to be trained into editorship craft continuously. In the midst of the pandemic, the training can be done through online courses. Hiring people (e.g., a native copyeditor) may also increase the work quality. Although this will cost more money, it is worth the effort for progress. Setting up a functional peer-review system should also be considered. During the course, try to set certain shortterm, mid-term, and long-term smart objectives and stick to the deadlines.

On account of the willingness we have witnessed, we believe that the Indonesian editors can solve the existing obstacles to make their journals gain the world acceptance and attain their international stance. Making local and regional associations of medical editors (e.g., Indonesian Association of Medical Editors [IndAMed] ${ }^{13}$ and Asia Pacific Association of Medical Journal Editors [APAME]) active would further support this movement. The national authorities may object your policies and even disapprove the journal nationally. Still, we need to remember that "we want to establish an internationally recognized journal and follow international publication specifications and practices; it is up to you to approve it or leave it."

From ${ }^{1}$ Medical Journal of Indonesia; ${ }^{2}$ German-Indonesian Medical Association (DIGM); ${ }^{3}$ Past President, World Association of Medical Editors (WAME) pISSN: 0853-1773 • eISSN: 2252-8083 https://doi.org/10.13181/mji.ed.215313 Med J Indones. 2021;30:1-4 
Corresponding author:

Hans Joachim Freisleben

E-mail: hj.freisleben@t-online.de

\section{REFERENCES}

1. Marusic A, Marusic M. How to help a small medical journal become a part of the mainstream literature. Science Editor. 2000;23(3):81-3.

2. Moher D, Galipeau J, Alam S, Barbour V, Bartolomeos K, Baskin $\mathrm{P}$, et al. Core competencies for scientific editors of biomedical journals: consensus statement. BMC Med. 2017;15:167.

3. Habibzadeh F. How can developing countries succeed in biomedical journalism? Saudi Med J. 2004;25(1 Suppl):S6-7.

4. Habibzadeh F. Does the world need a new journal? Int J Occup Environ Med. 2010;1(1):ii.

5. Centers for Disease Control and Prevention (CDC). Tuberculosis: data \& statistics [Internet]. Available from: https://www.cdc. gov/tb/statistics/default.htm.

6. Statistics Management Unit of Communication, Informatics and
Statistics Office DKI Jakarta. Tuberculosis in DKI Jakarta until 2018 [Internet]. Available from: http://statistik.jakarta.go.id/ penyakit-tuberkulosis-di-dki-jakarta-hingga-tahun-2018/.

7. Horton R. Offline: Indonesia-unravelling the mystery of a nation. Lancet. 2016;387(10021):830.

8. Ding D, Nguyen B, Gebel K, Bauman A, Bero L. Duplicate and salami publication: a prevalence study of journals policies. Int J Epidemiol. 2019;49(1):281-8.

9. Rochmyaningsih D. How to shine in Indonesian science? Game the system [Internet]. Science; 2019 Jan 8. Available from: https://www.sciencemag.org/news/2019/01/how-shineindonesian-science-game-system.

10. Habibzadeh F. Inclusion of the IJOEM in MEDLINE (Index Medicus). Int J Occup Environ Med. 2013;4(1):1.

11. Nafrialdi, Widjaja FF. The dream comes true-start for the new beginning. Med J Indones. 2016;25(1):1.

12. Habibzadeh F. We say what we mean and we mean what we say. Int J Occup Environ Med. 2010;1(3):107.

13. Nafrialdi. Editor's note: twenty two years of the Medical Journal of Indonesia. Med J Indones. 2013;22(1):1. 